\begin{tabular}{ll}
\hline \hline MINING AND METALLURGY INSTITUTE BOR & ISSN: 2334-8836 (Štampano izdanje) \\
UDK: 622 & ISSN: 2406-1395 (Online) \\
\hline \hline
\end{tabular}

\title{
SUPPLIER RANKING IN THE PUBLIC COMPANY FOR UNDERGROUND COAL EXPLOITATION RESAVICA IN AN ASPECT OF DELIVERY
}

\begin{abstract}
The aim of this paper is to show the application of multi-criteria analysis (PROMETHEE method) in the selection of suppliers that operate in the mining systems, specifically in the Public Company for the Underground Exploitation of Coal Resavica (PCUEC Resavica)- Serbia. The company ranking was done in terms of delivery according to five criteria. The criteria cover the most prominent aspects of the delivery management of suppliers. Accordingly, 5 suppliers were taken into consideration. In the ranking process the expert knowledge of specialists from the PCUEC Resavica was used. Firstly, the determination of importance and impact of certain criteria to the process of supplier selection was done, and after that the assessment of suppliers according to each criterion is performed by the company experts. The PROMETHEE method is used for the final ranking of suppliers. The obtained results show that the applied combined method gives the excellent results and it can be used for solving a large scale of complex problems in mining systems.

Keywords: supplier selection; production systems; ranking; mining systems; PROMETHEE
\end{abstract}

\section{INTRODUCTION}

Suppliers selection is one of the most important tasks for mining managers with aim to create a long-term sustainability and stability of the company. The supplier selection process implies application of different statistical techniques, as well as the MultiCriteria Decision Making methods [1,2]

The multi-criteria analysis methodology represents a good basis for solving the proposed problem. This methodology allows managers to obtain a priority list, based on ranking the alternatives by many different, opposite and often contradictory criteria at the same time. Also, the decision maker must have a big amount of relevant data for analysis in order to obtain the correct results. The most well-known methods are the analytic hierarchy process (AHP), analytic network process (ANP), TOPSIS and PRO-
METHEE. The PROMETHE method has many advantages compared to the other methods. The most important advantage is its capacity for obtaining the results in the contradictory condition and criteria.

The basic aim of this paper is to solve the supplier selection problem applying the PROMETHEE method based on the expert knowledge of specialists from the mining company for ranking of their suppliers in terms of delivery. The researches have been done in the PCUEC Resavica (case study).

The ranking process is done by the Decision Lab software which supports the PROMETHEE method and enables sensitivity analysis. Also, this software supports the visual tool called the GAIA plan for identification of conflicts among criteria and for grouping of the alternatives [3].

\footnotetext{
*University "Union-Nikola Tesla" Belgrade - Faculty of applied sciences Nis
} 


\section{PROMETHEE METHOD}

The PROMETHEE is a ranking method based on the selection of the best preference function and the weight coefficients for each criteria (Brans et al., 1984). Preference function determines the way of ranking a certain alternative according to another alternative and translates the deviation between them. The PROMETHEE method has at its disposal 6 forms of preference (Usual, U shape; V- shape; Level, Linear, Gaussian). Each form depends on two indifference thresholds (Q and $\mathrm{P})$. Threshold $(\mathrm{Q})$ represents the maximum deviation which the decision maker sees as unimportant, while the indifference threshold $(\mathrm{P})$ represents the minimum deviation which is considered to be important for the decision maker. Treshold Q must not be higher than P. Gaussian threshold (s) is the intermediate value of $\mathrm{P}$ and Q thresholds [4,5].

The PROMETHEE method calculates the positive-entrance flow $\left(\Phi^{+} \rightarrow 1\right)$, and the negative-exit flow $\left(\Phi^{-}\right)$for each alternative according to the outranking relations, in accordance with weight coefficients for each criterion. The positive preference flow shows the significance of a certain alternative, i.e. the higher value $\left(\Phi^{+} \rightarrow 1\right)$, the more significant is the alternative. The negative preference flow $\left(\Phi^{-}\right)$shows how a certain alternative is preferred in accordance with the other alternatives. The smaller value of the exit flow $\left(\Phi^{-} \rightarrow 0\right)$ indicates more significant alternative.

Complete ranking (PROMETHEE II) is based on the value of the net flow $(\Phi)$, which represents the difference between the positive and the negative preference flow. The best ranked alternative is the one with the highest value of the net flow [6].

\section{CASE STUDY}

The Public Company for the Underground Exploitation of Coal Resavica (PCUEC Resavica) - Serbia is a very complex system for coal exploitation and processing in Serbia. This system has eight mines located in the central part of Serbia (Figure 1).

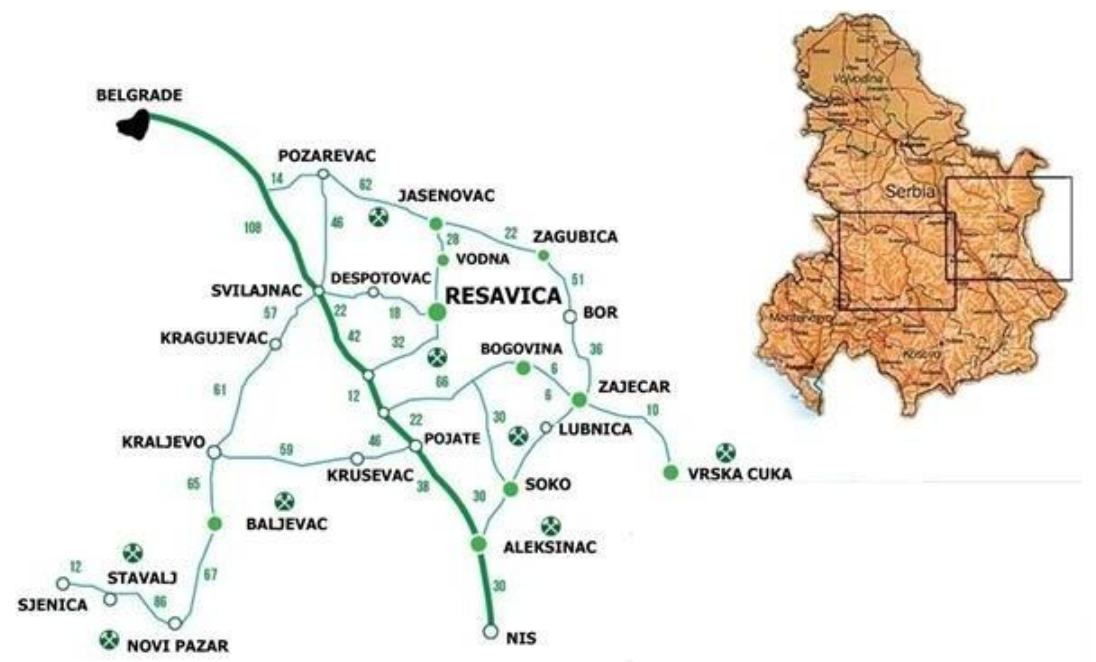

Figure 1 Mines of PCUEC Resavica 
The complex system like this demands a wide range and reliable suppliers which can meet its needs. In this paper is proposed the model of supplier selection according to the provided delivery of services and goods to the PCUEC Resavica. The model consists several phases - Figure 2.

Creation of selection committee is the first step. It consists of procurement experts and technical executives from the company. They identify the criteria and determine their impact, as well as the supplier's assessment of each criteria.
Criteria identification is the next step, which is extremely important for supplier selection. The criteria represent one of the most important factors for the process of supplier ranking. In this paper, the focus is on the delivery of services by suppliers to PCUEC Resavica. The most important criteria of delivery defined by selection committee are: the time required for the manufacture of products (C1), delivery reliability (C2), component safety and security (C3), adequacy of packaging standards (C4) and degree of product match (C5).

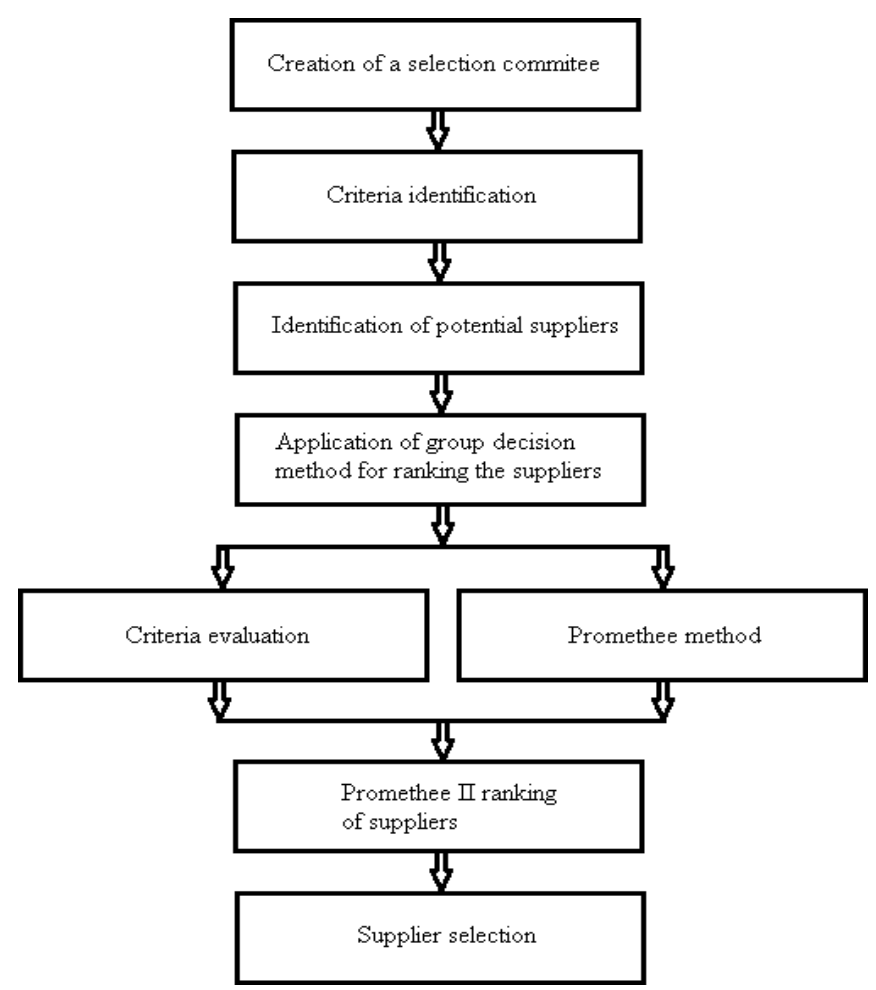

Figure 2 Proposed model for supplier selection

Identification of potential suppliers is next step of a selection model. For supplying of the PCUEC Resavica apply several suppliers. In this paper are identified five potential suppliers which are labeled $1 ; 2$; $3 ; 4$ and 5 .
The next step is application of a group decision method for ranking the suppliers. This is the most important, but also the most complex stage of the proposed decision model. This is executed by ten experts from the PCUEC Resavica (E1 - E10) who are 
directly involved with suppliers and who use the products and services provided by the suppliers (members of the selection commitee - managers, supervisors, employees in the procurement departments, employees in the manufacturing and maintenance sectors).

Their first task was to evaluate criteria, i.e. to determine the weight coefficients which represent their magnitude of the impact to the result of ranking of the suppliers. The weight coefficients of a criteria is determined by each expert, by filling the table grading the importance of the criteria from 0 to 1 , where the sum of all weight coefficients should be 1 . Table 1 shows the results of criteria evaluation, as well as the middle value of their weight coefficients.

Table 1 Value of criteria weight coefficients obtained from the experts, as well as their middle value

\begin{tabular}{cccccccccccc}
\hline $\begin{array}{c}\text { Expert } \\
\text { Criteria }\end{array}$ & E1 & E2 & E3 & E4 & E5 & E6 & E7 & E8 & E9 & E10 & $\begin{array}{c}\text { Middle } \\
\text { value }\end{array}$ \\
\hline C1 & 0.2 & 0.3 & 0.3 & 0.35 & 0.45 & 0.4 & 0.28 & 0.3 & 0.25 & 0.3 & 0.313 \\
C2 & 0.3 & 0.35 & 0.3 & 0.35 & 0.25 & 0.35 & 0.25 & 0.35 & 0.25 & 0.3 & 0.309 \\
C3 & 0.3 & 0.15 & 0.2 & 0.1 & 0.15 & 0.15 & 0.18 & 0.15 & 0.25 & 0.2 & 0.169 \\
C4 & 0.1 & 0.1 & 0.1 & 0.1 & 0.1 & 0.2 & 0.2 & 0.1 & 0.20 & 0.1 & 0.118 \\
C5 & 0.1 & 0.1 & 0.1 & 0.1 & 0.05 & 0.09 & 0.09 & 0.1 & 0.05 & 0.1 & 0.090 \\
\hline Sum & 1 & 1 & 1 & 1 & 1 & 1 & 1 & 1 & 1 & 1 & 1 \\
\hline
\end{tabular}

After criteria evaluation. the PROMETHEE method is used for evaluation the suppliers. Due to the qualitative or uncertain structure (assessment of suppliers) of the decision process. the appropriate qualitative five levels scale is used to enable quality comparison of the suppliers. Table 2 shows the qualitative scale with the numeral value for each qualitative mark.

Table 2 Qualitative scale

\begin{tabular}{lccccc}
\hline Qualitative value & Very low & Low & Middle & High & Very high \\
Numeral value & 1 & 2 & 3 & 4 & 5 \\
\hline
\end{tabular}

In order to create the evaluation matrix for PROMETHEE method, the evaluation of the suppliers in respect to the criteria has to be done. This is done by the same ten experts from the PCUEC Resavica. They have filled the table thus assessing the suppliers with marks given in Table 2. Table 3 shows the results of supplier assessments expressed through the middle value of all marks based on the marks given by all the experts.
After evaluation of the suppliers, the evaluation matrix for the PROMETHEE method is created (Table 4). The level shape of preference function is chosen according to the qualitative character of data for criteria and alternatives. The indifference and preference thresholds (Q and P) values are chosen in 5\% and $30 \%$ zones, respectively.

Table 3 Middle value of supplier marks in respect to the criteria

\begin{tabular}{cccccc}
\hline $\begin{array}{c}\text { Supplier } \\
\text { Criteria }\end{array}$ & Supplier 1 & Supplier 2 & Supplier 3 & Supplier 4 & Supplier 5 \\
\hline C1 & 2.8 & 4.2 & 4.3 & 4.1 & 4.5 \\
C2 & 3.1 & 4.8 & 4.9 & 4.2 & 4.7 \\
C3 & 3.6 & 4.6 & 4.6 & 4.7 & 4.5 \\
C4 & 3.0 & 4.4 & 4.5 & 4.6 & 4.8 \\
C5 & 3.1 & 4.5 & 4.3 & 4.6 & 4.7 \\
\hline
\end{tabular}


Table 4 Evaluation matrix

\begin{tabular}{lllllll}
\hline \multicolumn{1}{c}{ Criteria } & \multicolumn{1}{c}{ C1 } & \multicolumn{1}{c}{ C2 } & \multicolumn{1}{c}{ C3 } & \multicolumn{1}{c}{ C4 } & \multicolumn{1}{c}{ C5 } \\
\hline Max/min & $\max$ & $\max$ & $\max$ & Max & Max \\
Weight coeff. & 0.313 & 0.309 & 0.169 & 0.119 & 0.090 \\
Function of preference & Level & Level & Level & Level & Level \\
Supplier 1 & 2.8 & 3.1 & 3.6 & 3.0 & 3.1 \\
Supplier 2 & 4.2 & 4.8 & 4.6 & 4.4 & 4.5 \\
Supplier 3 & 4.3 & 4.9 & 4.6 & 4.5 & 4.3 \\
Supplier 4 & 4.1 & 4.2 & 4.7 & 4.6 & 4.6 \\
Supplier 5 & 4.5 & 4.7 & 4.5 & 4.8 & 4.7 \\
\hline
\end{tabular}

Base on the evaluation matrix, the soft- the value of the positive $\left(\Phi^{+}\right)$, negative $\left(\Phi^{-}\right)$ ware Decision Lab is used for evaluation the and net flows $(\Phi)$ for suppliers ranking tasuppliers (alternatives). Table 5 shows ken from the Decision Lab software.

Table 5 PROMETHEE preference flows

\begin{tabular}{cccc}
\hline Alternatives & $\boldsymbol{\Phi}^{+}$ & $\boldsymbol{\Phi}^{-}$ & $\Phi$ \\
\hline Supplier 1 & 0.0000 & 0.4367 & -0.4367 \\
Supplier 2 & 0.1039 & 0.0000 & 0.1039 \\
Supplier 3 & 0.1039 & 0.0000 & 0.1039 \\
Supplier 4 & 0.1039 & 0.0000 & 0.1039 \\
Supplier 5 & 0.1250 & 0.0000 & 0.1250 \\
\hline
\end{tabular}

The complete ranking of suppliers is Here, the values of flows $(\Phi)$ from the last done by the PROMETHEE II (Figure 3). column of Table 5 are used for ranking.

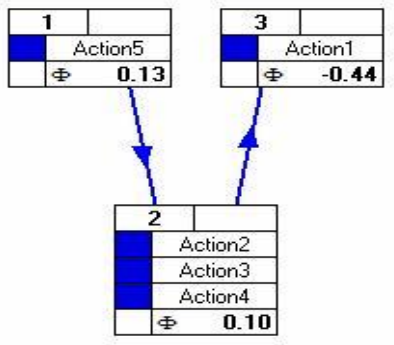

Figure 3 PROMETHEE II complete suppliers ranking

According to the PROMETHEE II complete ranking, the best alternative is the supplier 5. The other suppliers are ranked in this order: supplier 2, supplier 3, supplier 4 and supplier 1 (Figure 3).

The last step of the proposed model is a supplier selection. On the basis of realized complete procedure defined by the applied model of decision making, i.e. choosing the best supplier in terms of quality of goods and services for the PCUEC Resavica, it was decided that the best one is supplier 5. So, the supplier 5 is finally selected for the future procurement,

\section{ANALYSIS OF THE OBTAINED RESULTS}

The analysis starts from criteria. All criteria can be divided into two global groups 
in terms of their importance for suppliers ranking. The first group of criteria consists of the most influential criteria - $(\mathrm{C} 1)$ the time required for manufacture of products, (C2) delivery reliability, (C3) component safety and security.

The second group of criteria consists of less influential criteria (about $10 \%$ for each one) - (C4) adequacy of packaging standards. (C5) degree of product match. This indicates that adequacy of packaging standards. degree of product match is much less acceptable by the experts. According to this. for experts are much more important the criteria that enable the selection of better suppliers - criteria from the first group.

As far as suppliers are concerned. the best one is supplier 5. This supplier has the best marks from the aspect of criteria $\mathrm{C} 1$ the time required for the manufacture of products. C4- packaging standards and C5degree of product match. From the aspect of the rest of the criteria. this supplier has got good marks. They are a little below level comparing with the second ranked suppliers 2.3 and 4.

On the second place in ranking are supplier 2. 3 and 4. Those suppliers have a bit weaker or almost the same marks, compared to the first ranked supplier in all criteria. They have very similar marks, compared to each other. Based on the overall rating, they are identical in strength and ranked on the second place.

The last place is taken by the supplier 1, which is the lowest rated in terms of all criteria.

Based on the obtained results, the advantage needs to be given to the supplier 5 which is the best compared with the other suppliers.

\section{CONCLUSION}

In this paper is applied the PROMETHEE decision method for ranking of suppliers in the PCUEC Resavica in terms of the delivery of their goods and services. Based on the ranking results. the best suppliers are selected in order to provide a long- term sustainability and stability of the company. Five suppliers (supplier 1. 2. 3. 4 and 5 ) are analyzed in this process in terms of five criteria for ranking - the time required for the manufacture of products $(\mathrm{C} 1)$, delivery reliability $(\mathrm{C} 2)$, component safety and security (C3), adequacy of packaging standards (C4) and degree of product match (C5). Based on the obtained results by the PROMETHEE method, the best supplier is selected which is supplier 5. The most influential criterion for ranking is the criteria $\mathrm{Cl}$ (the time required for the manufacture of products)

\section{REFERENCES}

[1] WU. D. and OLSON. D. L. (2008) Supply Chain Risk, Simulation, and Vendor Selection. International Journal of Production Economics. 114(2). pp. 646-655

[2] CHAI. J., LIU. J.N.K. and NGAI. E.W.T. (2013) Application of DecisionMaking Techniques in Supplier Selection: A Systematic Review of Literature. Expert Systems with Applications. 40(10). pp. 3872-3885

[3] ALBADVI. A. CHAHARSOOGHI S.K. and ESFAHANIPOUR. A. (2007) Decision Making in Stock Trading: An Application of PROMETHEE. European Journal of Operational Research. 177(2). pp. 673-683

[4] Brans. J. P. (1982). The Engineering Decision: Developing Tools for Decision Support. Université Laval Québec. Canada. 183-213

[5] Brans. J. P., Mareschal. B., Vincke. P. H. (1984). PROMETHEE: A New Family of Outranking Methods in Multi-Criteria Analysis. Operational Research. North-Holland. Amsterdam. 477-490

[6] Brans. J.P., Mareschal. B. (1994). The PROMCALC and GAIA Decision Support System for MCDA. Decision Support System. 12. 297-310 